\title{
RESEARCH
}

Open Access

\section{Discovery of a novel integron-borne aminoglycoside resistance gene present in clinical pathogens by screening environmental bacterial communities}

\author{
Maria-Elisabeth Böhm ${ }^{1,2}$, Mohammad Razavi ${ }^{1,2}$, Nachiket P. Marathe ${ }^{1,2,3}$, Carl-Fredrik Flach ${ }^{1,2}$
}

and D. G. Joakim Larsson ${ }^{1,2^{*}}$

\begin{abstract}
Background: New antibiotic resistance determinants are generally discovered too late, long after they have irreversibly emerged in pathogens and spread widely. Early discovery of resistance genes, before or soon after their transfer to pathogens could allow more effective measures to monitor and reduce spread, and facilitate geneticsbased diagnostics.

Results: We modified a functional metagenomics approach followed by in silico filtering of known resistance genes to discover novel, mobilised resistance genes in class 1 integrons in wastewater-impacted environments. We identified an integron-borne gene cassette encoding a protein that conveys high-level resistance against aminoglycosides with a garosamine moiety when expressed in E. coli. The gene is named gar (garosamine-specific aminoglycoside resistance) after its specificity. It contains none of the functional domains of known aminoglycoside modifying enzymes, but bears characteristics of a kinase. By searching public databases, we found that the gene occurs in three sequenced, multiresistant clinical isolates (two Pseudomonas aeruginosa and one Luteimonas sp.) from Italy and China, respectively, as well as in two food-borne Salmonella enterica isolates from the USA. In all cases, gar has escaped discovery until now.

Conclusion: To the best of our knowledge, this is the first time a novel resistance gene, present in clinical isolates, has been discovered by exploring the environmental microbiome. The gar gene has spread horizontally to different species on at least three continents, further limiting treatment options for bacterial infections. Its specificity to garosamine-containing aminoglycosides may reduce the usefulness of the newest semisynthetic aminoglycoside plazomicin, which is designed to avoid common aminoglycoside resistance mechanisms. Since the gene appears to be not yet common in the clinics, the data presented here enables early surveillance and maybe even mitigation of its spread.
\end{abstract}

Keywords: Functional metagenomics, Antibiotic resistance, Pathogens, Environment, Aminoglycosides, Integron

\footnotetext{
* Correspondence: joakim.larsson@fysiologi.gu.se

${ }^{1}$ Centre for Antibiotic Resistance Research (CARe), University of Gothenburg, Gothenburg, Sweden

2Department of Infectious Diseases, Institute of Biomedicine, Sahlgrenska Academy, University of Gothenburg, Gothenburg, Sweden

Full list of author information is available at the end of the article
}

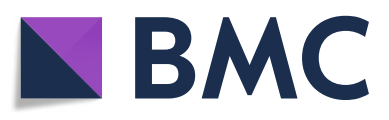

(c) The Author(s). 2020 Open Access This article is licensed under a Creative Commons Attribution 4.0 International License, which permits use, sharing, adaptation, distribution and reproduction in any medium or format, as long as you give appropriate credit to the original author(s) and the source, provide a link to the Creative Commons licence, and indicate if changes were made. The images or other third party material in this article are included in the article's Creative Commons licence, unless indicated otherwise in a credit line to the material. If material is not included in the article's Creative Commons licence and your intended use is not permitted by statutory regulation or exceeds the permitted use, you will need to obtain permission directly from the copyright holder. To view a copy of this licence, visit http://creativecommons.org/licenses/by/4.0/ The Creative Commons Public Domain Dedication waiver (http://creativecommons.org/publicdomain/zero/1.0/) applies to the data made available in this article, unless otherwise stated in a credit line to the data. 


\section{Background}

Mobile resistance factors accumulate in human pathogens via horizontal transfer, often from environmental bacteria or commensals [1]. To the best of our knowledge, every resistance factor that is a clinical problem today was discovered long after it irreversibly emerged and spread in pathogenic bacteria widely enough to cause treatment failures. After discovery, propagation can often be tracked in retrospect from country to country. One of the most prominent examples is the first detection of the mobile colistin resistance gene $m c r-1$ in 2015 followed by documentation of its worldwide presence [2].

If we could identify new resistance threats before they spread widely or even before they appear in pathogens, actions could be taken to reduce the risks of their emergence, spread and clinical consequences. Such actions include targeted monitoring, confinement and the addition of the new genes to genetics-based diagnostics. Moreover, the development of new antibiotics can benefit from the awareness of novel resistance mechanisms.

Large-scale functional screening of metagenomic DNA from microbial communities has revealed many unknown resistance genes in various environments [3, 4]. The approach is independent of the cultivability of the indigenous bacterial host and does not rely on similarity to known genes, making it suitable for the identification of novel resistance determinants [5]. Functional metagenomics cannot, however, easily discriminate between mobile and immobile genes, the latter having less potential of transfer to and between pathogens [6]. Moreover, common resistance genes will dominate the sequenced clones, reducing the likelihood of identifying rare, novel genes.

Integrons are genetic elements that acquire, shuffle and express promoter-less gene cassettes. Although not mobile themselves, integrons are often associated with mobile elements and located on conjugative plasmids [7]. This combination makes them ideal for acquisition and spread of resistance genes to and among pathogens, particularly integrons of class 1 [8].

The aim of this study was to discover rare, novel resistance determinants that may appear in pathogens or that have already emerged in pathogens but thus far escaped identification. We explored bacterial communities from river sediments contaminated with wastewater in a country with a high use of antibiotics (India) [9] by adapting a functional metagenomics approach focusing on amplicon libraries of integron gene cassettes. Blunt-end cloning into a plasmid under the control of a constitutively active promoter allowed us to screen for resistance against different antibiotics. To overcome sensitivity limitations, we did not analyse individual resistant clones but rather amplified and sequenced inserts of all growing bacteria on the plates via long-read technologies. We then filtered out highly abundant known resistance genes in silico to identify rare, new putative resistance genes.

\section{Results and discussion}

To identify mobilised novel resistance determinants, class 1 integron gene cassette libraries were prepared under control of the constitutively active $\mathrm{P}_{\text {bla }}$ promoter in $E$. coli $\mathrm{DH} 10 \beta \mathrm{pZE} 21-\mathrm{P}_{\text {bla }}$. Library sizes ranged from $5.0 \times 10^{9}$ to $1.8 \times 10^{10} \mathrm{bp}$. The estimated average insert size of all libraries ranged from 600 to $1000 \mathrm{bp}$. Libraries were screened for functional resistance determinants on 13 different antibiotics at three different concentrations (Additional file 5). No resistance against tigecycline or nitrofurantoin was detected. The other antibiotics resulted in at least 15 to up to several thousand colonies on each screening plate. All colonies were scraped off and barcoded amplicons were prepared for long-read sequencing (PacBio Sequel). Amplicon sequencing resulted in 419,709 reads. Based on the retrieved barcodes, 382, 332 could be assigned to the antibiotics and concentrations used to select resistant clones. We then predicted open reading frames (ORFs) and filtered out all reads containing known antibiotic resistance genes (ARGs) responsible for the respective phenotype. Known ARGs were defined as the ORFs with identity greater than $95 \%$ and coverage greater than $85 \%$ to their homologues in the ResFinder database. The remaining 147,151 reads consisted of 46,403 unique reads ( $11 \%$ of all reads) with an average length of $1540 \mathrm{bp}$ and they included 48,562 unique predicted ORFs. Each of the selection amplicons resulted in an average of 1450 reads with no known ARGs. These were searched manually for resistance gene candidates.

To identify promising putative novel resistance genes, we used five criteria: An ORF needed to be (i) complete and (ii) highly abundant in its set of reads while (iii) not common in the other selection sets. To ensure that the ORF originated from an integron (iv) both binding sites for the primers used to amplify the gene cassettes should be present in the read. Furthermore, (v) the candidate ORF should be the only ORF present that could explain the resistance phenotype. Despite the large number of colonies growing during functional selection, only the gentamicin and $\beta$-lactam selection sets contained ORFs fulfilling all mentioned criteria (Table 1). Thus, the metagenomic DNA samples used in this study contain exceptionally high amounts of class 1 integrons carrying a multitude of antibiotic resistance genes [10, 11], but most of them were filtered out as known or close variants of known ARGs.

Using this approach, candidate ORFs with little or no resemblance to any known resistance factor were chosen for functional verification. The putative, completely novel 
Table 1 Abundance of candidate ORFs for functional selection

\begin{tabular}{|c|c|c|c|c|c|}
\hline & & gar & ORF 1 & ORF 2 & ORF 3 \\
\hline Predicted functional domain & & P-loop NTPase & None & partial S41-like peptidase & DUF1851 \\
\hline Length [bp] & & 504 & 816 & 867 & 438 \\
\hline \multirow[t]{11}{*}{ Abundance in selection sets } & cefotaxime & 0 & 416 & 18 & 25 \\
\hline & chloramphenicol & 8 & 12 & 0 & 0 \\
\hline & ciprofloxacin & 7 & 5 & 0 & 0 \\
\hline & colistin & 0 & 10 & 0 & 0 \\
\hline & ertapenem & 8 & 1 & 0 & 14 \\
\hline & gentamicin & 1692 & 1 & 0 & 2 \\
\hline & imipenem & 26 & 1 & 0 & 1 \\
\hline & meropenem & 0 & 17 & 0 & 11 \\
\hline & rifampicin & 0 & 5 & 0 & 2 \\
\hline & sulfamethoxazole & 0 & 2 & 0 & 0 \\
\hline & trimethoprim & 16 & 1 & 0 & 0 \\
\hline
\end{tabular}

ORFs recovered from the set of unique reads were clustered with $97 \%$ identity threshold in each selection set. The size of clusters was reported as the abundance of candidate ORFs

resistance genes found in the read set selected by $\beta$ lactams did not confer resistance when synthesised and expressed in E. coli. It is possible that they were able to grow in close vicinity to resistant colonies during the functional selection, since $\beta$-lactamases are secreted into the periplasm and in outer membrane vesicles to inactivate $\beta$ lactam antibiotics [12-14]. Hence, they might simultaneously provide close-range protection for surrounding non-resistant bacteria, which appeared as false positives.

Resistance of the candidate gene highly selected on gentamicin (designated gar = garosamine-specific aminoglycoside resistance) was successfully verified in E. coli.
The protein GAR (167 aa) has an overall negative charge (pI 4.6). Since cation concentrations profoundly influenced the minimal inhibitory concentrations (MICs) (Table S1), we performed all subsequent experiments in cation-adjusted Mueller-Hinton broth. The expression of gar resulted in a 2760-fold MIC increase of gentamicin (Fig. 1).

Aminoglycoside modifying enzymes (AMEs) are the most clinically important resistance mechanism against aminoglycosides [15]. AMEs are divided into three enzymatic classes targeting $-\mathrm{OH}$ or $-\mathrm{NH}_{2}$ groups: aminoglycoside $\mathrm{N}$ acetyltransferases (AACs), $-O$-nucleotidyltransferases

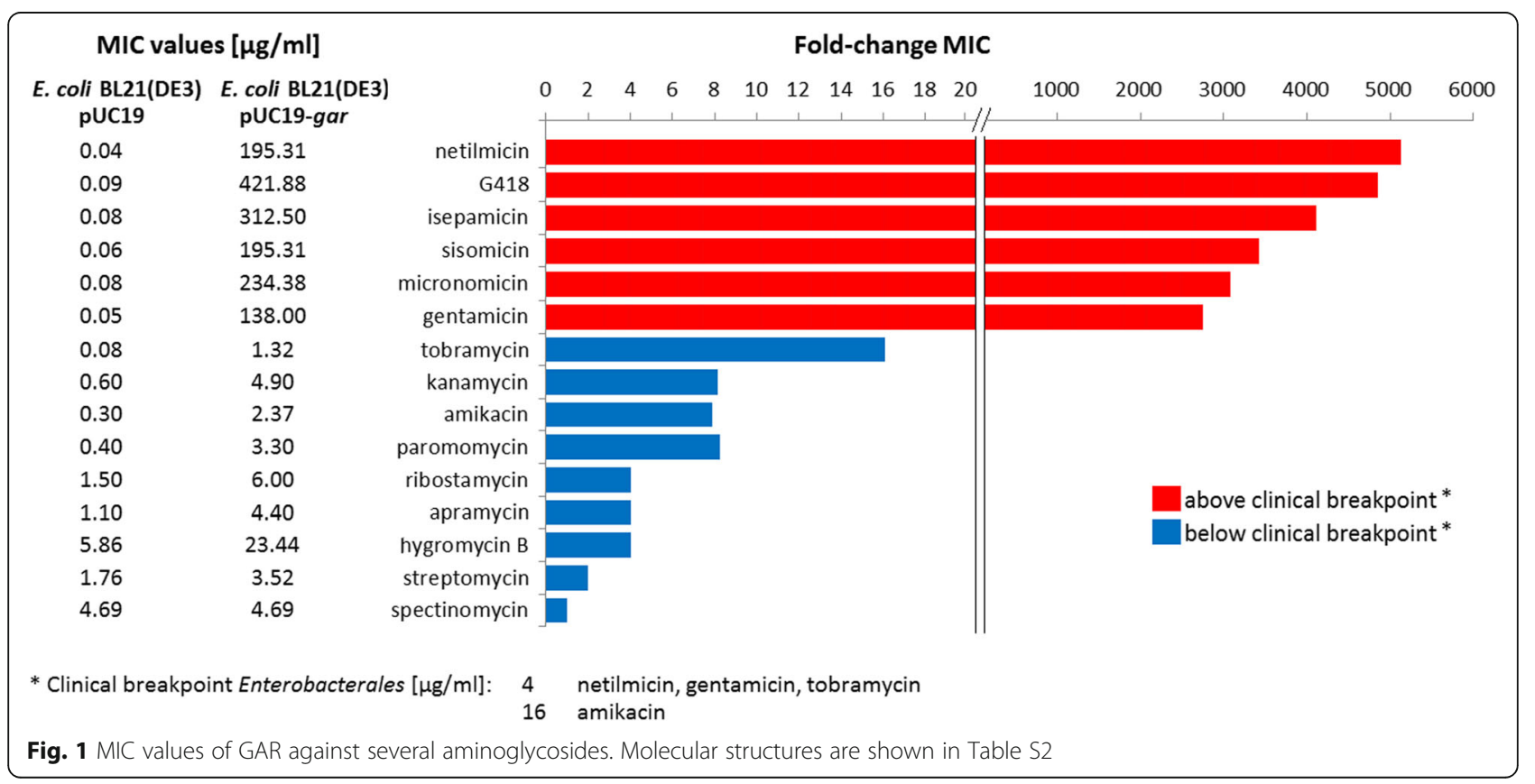


(ANTs) and -O-phosphotransferases (APHs). Each class possesses a unique pattern of activity against different aminoglycosides due to their specific targets in the molecular structure [16]. We therefore tested the effectiveness of GAR against at least one representative of each aminoglycoside subclass (Fig. 1). GAR conferred resistance specifically against all six tested 4,6-disubstituted 2-deoxystreptamine-aminoglycosides containing a garosamine residue (Table S2), suggesting that it is critical for recognition.

Aminoglycosides can cause mistranslation by targeting the negatively charged $16 \mathrm{~S}$ rRNA close to the aminoacyl-tRNA site of the 30S subunit [17]. The negative charge and garosamine-specific resistance pattern make the ribosomal RNA an unlikely target for GAR. GAR contains the Walker A NTP-binding motif involved in various phosphorylation reactions [18]. It also harbours two DxD motifs (Fig. 2). Such a motif provides the ability to bind the required $\mathrm{Mg}^{2+}[18,23,26]$. The presence of these two motifs and its negative charge strongly suggest that GAR is enzymatically active as a kinase with high affinity for positively charged targets. Aminoglycosides are indeed positively charged molecules that provide many hydroxyl residues for potential phosphorylation, including two at the garosamine moiety. One of these hydroxyl groups, located at the 4" carbon atom, has not yet been described as a target for an AME.

There is very little similarity between GAR and all known ARGs, including AMEs (less than 20\% amino acid identity). The phylogenetic tree of GAR and related proteins (Fig. 3) shows that GAR is clearly separated from the known AMEs and is located among proteins mostly annotated as hypothetical or AAA-domain containing proteins (kinases). The closest related protein from the NCBI non-redundant protein database $(51 \%$ identity, WP_135484108.1) is not assigned any function. GAR shares slight amino acid sequence identity (about 20\%) to tunicamycin resistance proteins (Fig. 2). Resistance to tunicamycin, a toxic nucleoside analogue produced by several Streptomyces species, is caused by ATP-binding membrane proteins, which also have a suspected phosphorylation activity [20,27].

Several studies have identified a range of new ARGs in environmental samples [4, 28-32]. However, the clinical implications are less clear, since only a minor fraction of these genes are likely to end up in pathogens, e. g. due to lack of mobility, limited ecological connectivity and high fitness costs $[3,6]$. Searching gar against the GenBank database resulted in 100\% and 99\% nucleotide identity with chromosomal regions of the clinical isolates Luteimonas sp. 83-4 (CP029556.1, China) and P. aeruginosa 105MG [33] (AJ786649.2, Italy), respectively. We additionally found gar on contigs of the clinical isolate
P. aeruginosa S742_C15_BS (NFFO01000062.1, Italy) and on contigs of the food-borne pathogens S. enterica ADRDL-2811 (AAKHBQ010000151.1, USA) and $S$. enterica subsp. enterica serovar Johannesburg FSIS1609335 (AAIUOI010000042.1, USA) isolated from poultry products. In neither case was the gar gene recognised as a resistance gene. We can show that gar appears as a gene cassette in several spatially, temporally and phylogenetically separated clinical isolates, so the gene has already overcome the barrier preventing most environmental ARGs from becoming clinically relevant. Combined with its absence in related isolates (none of the other currently available $P$. aeruginosa, Luteimonas sp. or S. enterica genomes or assemblies in GenBank contain gar), this provides evidence that the gar gene is mobile. Furthermore, P. aeruginosa 105MG and P. aeruginosa S742_C15_BS belong to the exceptionally successful multidrug-resistant $P$. aeruginosa ST235 and ST111 linages, respectively, which are predominant on five continents [34]. P. aeruginosa frequently causes nosocomial infections with high mortality rates, especially in patients with chronic diseases, due to the accumulation of resistances against aminoglycosides, $\beta$ lactams and fluoroquinolones [34, 35]. Salmonellosis is the most important food-borne illness in the USA and the second most common in the EU [36, 37]. Salmonella isolates have collected a multitude of aminoglycoside resistance genes, probably due to the long-term usage of this antibiotic class in food production [38]. Occurrence in several common multidrug-resistant pathogens increases the probability for horizontal gene transfer, (co-) selection and spread of gar.

The structure-specific resistance pattern of AMEs implies that a single resistance gene cannot confer resistance against all aminoglycosides. However, any ARG that adds resistance to any antibiotic, which could have been a treatment possibility, reduces clinical options for treatment. For instance, $P$. aeruginosa 105MG carries four AMEs (aph(3)-IIb, aac(6)-31, ant(3")-Ia, aac(6)-Il) plus gar, a combination that results in resistance against all tested aminoglycosides with the exception of apramycin (Table S3). The five AMEs target streptomycin/spectinomycin (ant(3")-Ia); the $-\mathrm{OH}\left(3^{\prime}\right)$ of kanamycin, G418, isepamicin, paromomycin and ribostamycin $(a p h(3)-I I b)$ and the $-\mathrm{NH}_{2}\left(6^{\prime}\right)$ of kanamycin, gentamicin, netilmicin, sisomicin, isepamicin, amikacin, tobramycin and ribostamycin $(\operatorname{acc}(6)-31, \operatorname{acc}(6)-I l)$ [16]. Thus, even in a strain already harbouring several AMEs, gar extends the resistance profile (micronomicin). Luteimonas sp. 83-4 contains two aminoglycoside resistance genes, an aph(3')-XV and gar (Table S4). Here, gar adds resistance to gentamicin, netilmicin, sisomicin and micronomicin, exacerbating already observed clinical multi-resistance. Resistance against garosamine-containing aminoglycosides is particularly 


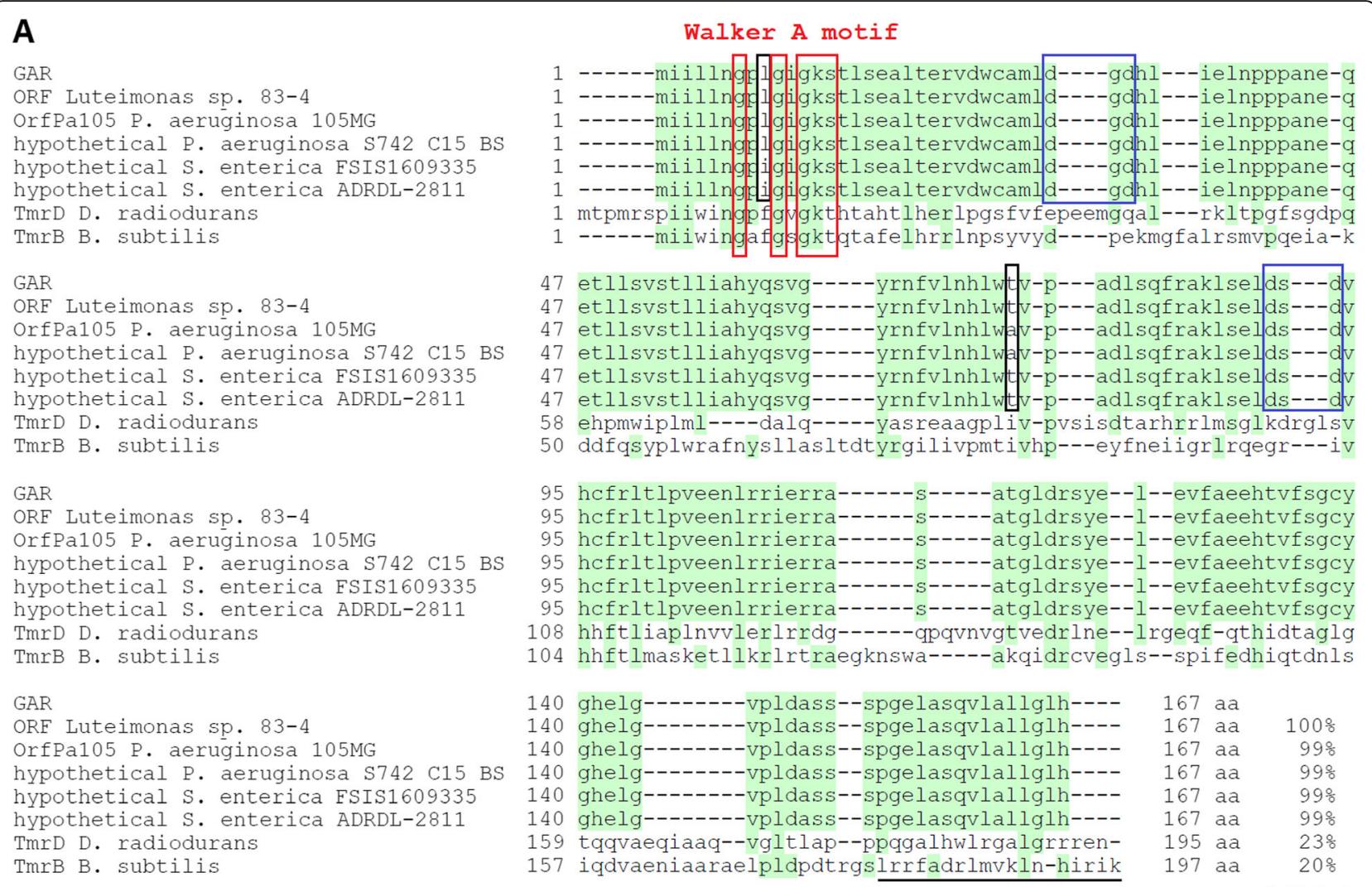

B

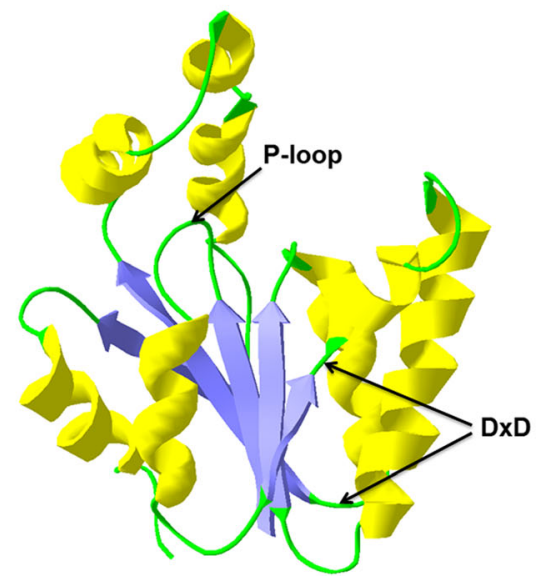

Fig. 2 Structural motifs of GAR and related proteins. a Alignment of GAR with related proteins. The two amino acids that differ between GAR variants (L91, T75A) are framed in black. The ORF from Luteimonas sp. 83-4 (CP029556) with 100\% identity to GAR has no annotation. OrfPa105 (AJ786649) from P. aeruginosa 105MG and the ORF from P. aeruginosa S742_C15_BS without annotation (NFFO01000062.1) are identical. They differ by two nucleotides and one amino acid (T75A) from GAR. The two ORFs from S. enterica ADRDL-2811 (AAKHBQ010000151.1) and S. enterica subsp. enterica serovar Johannesburg FSIS1609335 (AAIUOI010000042.1) are identical to each other, annotated as hypothetical proteins and differ by two nucleotides and one amino acid (L91) from GAR. Tunicamycin resistance protein TmrB as harboured by Bacillus subtilis (WP_003246258.1), the C-terminal membrane anchor is underlined [19], TmrD from Deinococcus radiodurans (WP_010888058.1) [20]. The N-terminal Walker A motif occurs in TmrB and in GAR, but the absence of the membrane anchor hints to a cytoplasmic location of GAR. The NTP-binding motif G/ AXXGXGKT/S (Walker A or P-loop) is marked by red rectangles [18, 21, 22]. Searching NCBI's conserved domain database revealed an AAA domain (ATPases Associated with diverse cellular Activities, pfam13238) within GAR and similarity to gluconate kinases (COG3265). GAR harbours no Walker B motif, but two potential DxD motifs, which could be responsible for $\mathrm{Mg}^{2+}$ binding [23], marked by blue rectangles. b Protein structure model of GAR. According to the structure model, the first DxD motif (aa 31-33) is located in the same cavity as the P-loop and thus more likely to participate in the NTP-binding and hydrolysis. GAR is shorter than other aminoglycoside phosphotransferases (APHs) and seems to contain five $\mathrm{N}$-terminal parallel $\beta$-sheets, while APHs contain five anti-parallel $\beta$-sheets in their $\mathrm{N}$-terminal domain $[24,25]$ 


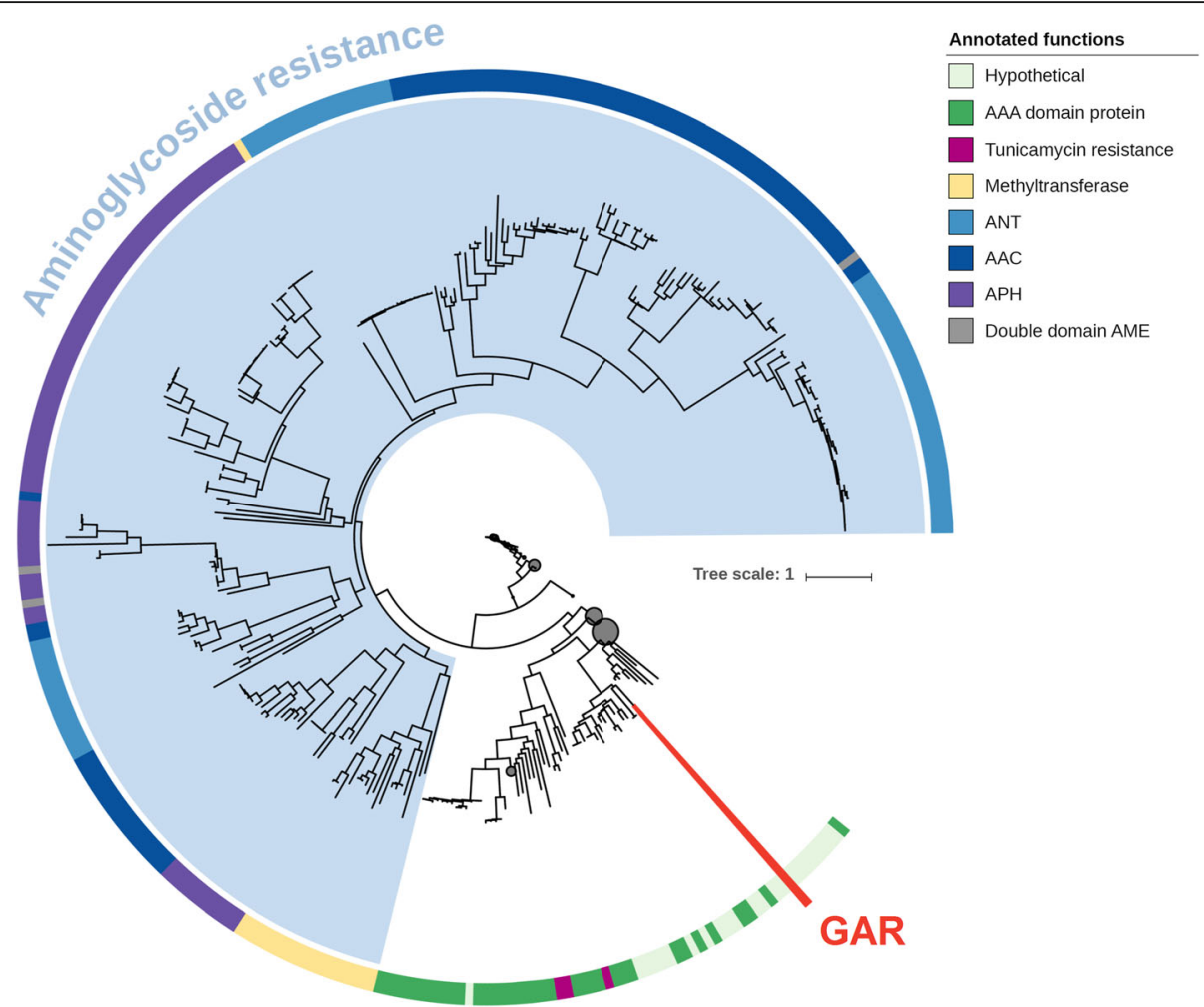

Fig. 3 Phylogenetic tree of aminoglycoside resistance enzymes, GAR and its 1000 closest related protein sequences. Clades are collapsed (dark circles) to improve visual comparisons

worrying, since the newest semisynthetic aminoglycoside plazomicin (FDA-approved for treatment of complicated urinary tract infections [39]), which is derived from sisomicin and designed to avoid most of the common AMEs [40], includes garosamine. In the light of more and more widespread resistance to e.g. all $\beta$-lactams, an increasing dependence on aminoglycosides presenting a target for gar implies a growing selective pressure for bacteria to acquire, keep and spread the gar gene.

To examine if gar is present on a conjugative element in the $P$. aeruginosa $105 \mathrm{MG}$ isolate available to us, we attempted to transfer its aminoglycoside resistance phenotype to $E$. coli or $P$. putida via conjugation, but could detect none. Nonetheless, considering that gar is harboured by three distantly related species, it can obviously move horizontally. To shed light on the mechanisms involved, the genome of $P$. aeruginosa 105MG (GenBank accession: VLOE00000000) was sequenced. The gar gene is located within a class 1 integron on a chromosomal scaffold of $1.18 \mathrm{Mb}$. The integron is flanked by $\operatorname{Tn} 3$ and $\operatorname{Tn} 21$ transposon elements, which are highly abundant in bacterial genomes [41-43]. Transposable elements can promote inter-cellular mobility of integrons by insertion into a conjugative plasmid or an integrative conjugative element (ICE). The contigs upstream of the class 1 integron of the two $P$. aeruginosa isolates containing the gar gene cassette are identical and harbour several genes encoding conjugal transfer proteins. Hence, the entire integron could have been aquired from a conjugative plasmid/ICE, e.g. via Tn 21 [44]. There are currently $261 \mathrm{P}$. aeruginosa genomes in NCBI's database of complete genomes, 74 of them (28\%) contain the complete intI1 gene (query cover and identity $\geq 97 \%)$, ten $(4 \%)$ of which are plasmid-borne, but only the 105MG isolate harbours gar. It is thus highly plausible that gar has been aquired as a cassette, probably from an integron located on a yet unidentified plasmid/ICE hosted transiently by $P$. aeruginosa 105MG.

We have identified gar in six gene cassette arrays in at least three species. These regions are within integrons and adjacent to known resistance gene cassettes, such as $a p h\left(3^{\prime}\right)-X V, b l a_{\mathrm{OXA}-2}$ and $b l a_{\mathrm{VIM}-1}$, providing resistance to a range of critically important antibiotics (Fig. 4). The identified genetic contexts show that gar has appeared as the first and only gene cassette in the integrons from PETL metagenomic samples, as the fifth in Luteimonas sp. 83-4, the third in P. aeruginosa 105MG, the fourth in $P$. aeruginosa S742_C15_BS and the first in both $S$. enterica isolates. Rearrangement of gene cassettes provides rapid adaptation in response to changing environments. The presence of gar in different contexts and pathogens not only shows that it could confer a selective 
A

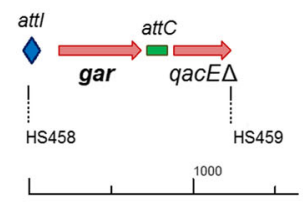

B

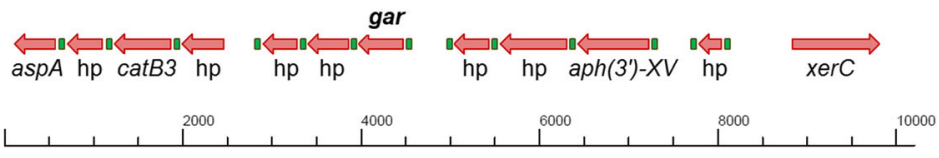

C

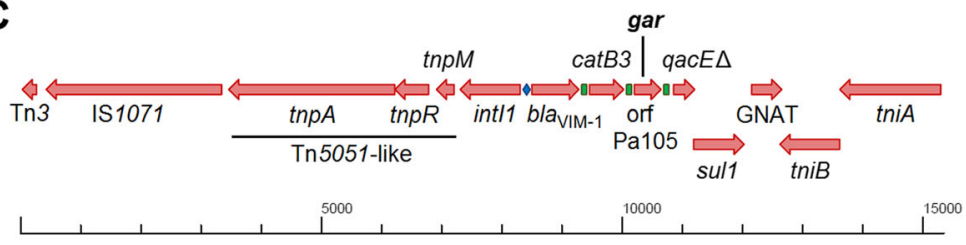

D
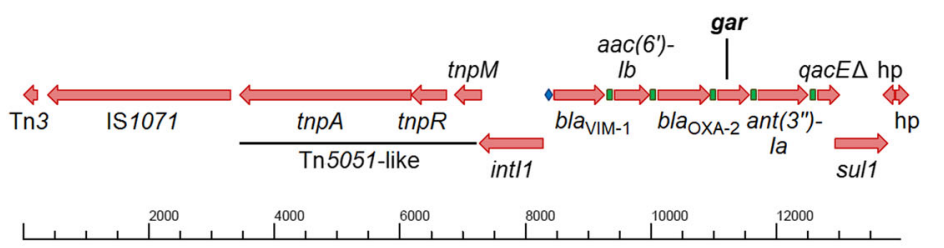

E

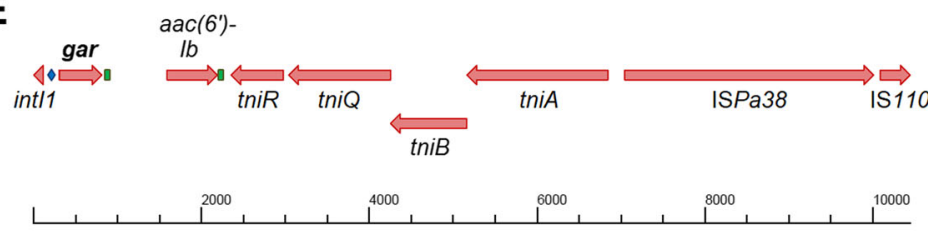

F
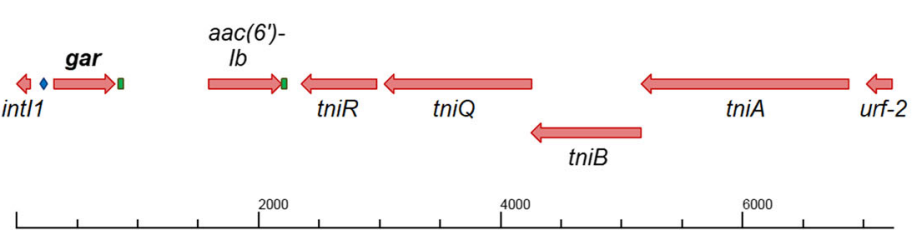

Fig. 4 Gar in the six identified genetic contexts. a PETL metagenomics DNA sample. Primers HS458-HS459 amplified the region between attl site and qacE $\Delta$ of a clinical class 1 integron (GenBank accession MN215968). b Luteimonas sp. 83-4 (CP029556.1), chromosomal, not annotated in the available contig sequence. c P. aeruginosa 105MG (AJ786649.2 and VLOE00000000), chromosomal, clinical class 1 integron, included in a Tn5051like transposon. Gar variant of $P$. aeruginosa $105 \mathrm{MG}=$ orfPa105, previously annotated as hypothetical protein. d P. aeruginosa S742_C15_BS (NFFO01000062.1), clinical class 1 integron, downstream context identical to $P$. aeruginosa 105MG, but lacking the Tn21-like region upstream. e $S$. enterica subsp. enterica serovar Johannesburg FSIS1609335 (AAIUOI010000042.1), class 1 integron, downstream flanked by Tn21 elements, ISPa38 and IS110. f S. enterica ADRDL-2811 (AAKHBQ010000151.1), downstream flanked by Tn21 elements. a, d-f Entire contig shown. Attachment sites: attl, marked as blue rhomb; attC, marked as green rectangle; hp, hypothetical protein; aspA, aspartate ammonia lyase; catB3, chloramphenicol transferase; $a p h\left(3^{\prime}\right)-X V$, aminoglycoside phosphotransferase; xerC, tyrosine recombinase (integrase); IS1071 (Tn3 family): single element, including transposase and flanking inverted repeats; Tn5051-like tnp region consisting of tnpA: transposase, tnpR: resolvase and tnpM: putative transposition regulator; int11, class 1 integron integrase; bla $a_{V I M-1}$, metallo- $\beta$-lactamase VIM-1; qacE $\Delta$, quarternary ammonium compound resistance protein (truncated); GNAT, Gcn5-related N-acetyltransferase; tniA-tniR and urf-2, thi region (Tn27-like); aac(6')-lb, aminoglycoside acetyltransferase; bla OXA-2, class D B-lactamase OXA-2; ant(3")-la, aminoglycoside nucleotidyltransferase; ISPa38 (Tn3 family); and an IS110 family element 
advantage for its hosts, but that it is a gene cassette accessible to diverse microbial communities and pathogens. Integrons are present in $20 \%$ of the sequenced $\gamma$ proteobacterial genomes [45]. Class 1 integrons in particular have become very successful in pathogens and highly abundant in various human-impacted environments [46, 47]. Any compatible plasmid containing a class 1 integron could acquire the gar cassette and facilitate further spread. Therefore, if ecological connectivity allows, gar can be integrated into the genomes of diverse bacterial hosts.

So far, gar is a rare but already widely dispersed gene in wastewater metagenomes from at least eight countries in Europe, Asia, Africa and Australia (Table S5). Additional transfer events to other pathogens are therefore plausible. Detection of gar only in wastewater-impacted environments, not in metagenomes from human individuals, is coherent with its presence in a small proportion of the human population. This implies that targeted investigations of wastewater would be suitable for both initial detection and monitoring, as a single sewage sample reflects the microbiota from a very large number of individuals [48].

\section{Conclusions}

Most clinically important resistance genes are discovered as a consequence of treatment failure or by screening clinical isolates. The combination of integron-focused functional metagenomics and in silico filtering of known resistances allowed us to explore environmental samples for already mobilised, novel resistance genes. With this approach, we discovered gar, a new mobile resistance gene providing high-level resistance against garosaminecontaining aminoglycosides. Despite its presence in the clinics, gar has evaded discovery as it does not resemble previously known aminoglycoside resistance genes. The knowledge presented here offers possibilities for early surveillance, actions to reduce transmission, gene-based diagnostics and ultimately improved treatment.

\section{Methods}

Detailed material and methods with references are found in Additional file 5.

\section{Bacterial strains}

Metagenomic library construction and functional screenings were conducted in E. coli DH10 $\beta$ (NEB). Functional verifications were performed in $E$. coli C600Z1 (Expressys) and GAR-induced increases in aminoglycoside MICs were determined in E. coli BL21(DE3) (Invitrogen). P. aeruginosa 105MG [33] was kindly supplied by Professors C. Giske and G. Rossolini.

\section{Metagenomic DNA samples}

DNA was extracted, pooled and amplified with three sets of primers targeting the gene cassette array of class 1 integrons from sediment samples collected from Mutha River (Pune, Maharashtra, India) and Isakavagu/Nakkavagu River (Patancheru Enviro Tech Ltd. (PETL) near Hyderabad, India) as described before [9]. In contrast to the previously performed amplification of the same samples [9], 5' phosphorylated primers were used to generate inserts for metagenomics libraries.

Metagenomic library preparation and functional selection To identify mobilised novel resistance determinants, class 1 integron gene cassette libraries were prepared and screened following the protocol by Forsberg et al. [3] with some modifications. The plasmid pZE21- $\mathrm{P}_{\text {bla }}$ (pZE21-MCS1 harbouring the constitutively active promoter $\mathrm{P}_{\text {bla }}$ ) was linearised, dephosphorylated and ligated with the amplified class 1 integron gene cassettes to create the libraries, which were electroporated into $E$. coli DH10ß.

For functional selection, $100 \mu \mathrm{l}$ of each metagenomic library was plated on $\mathrm{LB}+\mathrm{Kan}^{50}$ agar containing one of 13 different antibiotics (ciprofloxacin, trimethoprim, gentamicin, tigecycline, chloramphenicol, nitrofurantoin, rifampicin, cefotaxime, ertapenem, imipenem, meropenem, sulfamethoxazole and colistin) at three different concentrations $(4 \times$ MIC, $8 \times$ MIC and clinical breakpoint concentration). All colonies from a single plate were scraped off, resuspended in LB $+20 \%$ glycerol and frozen at $-80^{\circ} \mathrm{C}$.

\section{Amplicon-PCR and sequencing}

Pooled antibiotic resistant clone libraries were used as PCR templates to prepare amplicons with barcoded primers that allowed allocation of the antibiotics and concentrations used for selecting clones. Amplicons were combined into two pools (16 amplicons each), and sequencing libraries were prepared from each pool using SMRTbell $^{\mathrm{Tm}}$ Template Prep Kit 1.0-SPv3. The two libraries were sequenced on separate PacBio Sequel ${ }^{\text {mi }} \mathrm{SMRT}^{\circ}$ cells in the Science for Life Laboratories (Uppsala, Sweden).

\section{Integron amplicon read analysis}

Open reading frames were predicted using Prodigal [49] (v2.6.3). The predicted ORFs were searched against NCBI's non-redundant protein database (last update 13.04.2017) and ResFinder [50] (last update 15.04.2018) using Diamond [51] (v0.9.24.125). We defined known ARGs as ORFs with identities greater than $95 \%$ and coverage greater than $85 \%$ to their homologues in the ResFinder database. Reads that contained known ARGs responsible for the respective phenotype were filtered out. 
To identify promising putative novel resistance genes, a manual search of the read sets for complete ORFs that were highly abundant in their set of reads followed. Presence of the cassette amplification primers was required to ensure that the ORF originated from an integron and that it was solely responsible for the resistance phenotype.

\section{Functional verification of novel resistance genes}

Resistance gene candidates were synthesised and tested in E. coli C600Z1 pZE21-MCS1 as described earlier [9]. Subsequently, gar was inserted into pUC19, replacing the bla gene and transformed into E. coli BL21(DE3) to test it in an expression system without any aminoglycoside resistance.

\section{MIC determination}

Minimal inhibitory concentrations (MICs) were determined by broth microdilution in cation-adjusted Mueller-Hinton medium. Serial dilutions of tested antibiotics were prepared in triplicate in 96-well plates and inoculated with $5 \times 10^{5}$ cells $/ \mathrm{ml}$ per well (CLSI standard [52]) at a final volume of $200 \mu \mathrm{l}$. After $24 \mathrm{~h}$ incubation at $37^{\circ} \mathrm{C}$ and $180 \mathrm{rpm}$, the optical density was measured and $\mathrm{MIC}$ was defined as the lowest concentration of an antimicrobial that reduced growth to $\mathrm{OD}_{650} \leq 0.2$ [53].

\section{Whole genome sequencing}

Genomic DNA was isolated using the DNeasy Blood \& Tissue Kit (Qiagen) and sent to FIMM Technology Centre in Helsinki, Finland, for next generation sequencing. The KAPA HyperPlus Kit was used for library preparation and paired-end sequencing was performed on a MiSeq (Illumina). The paired-end datasets were filtered and trimmed using the Trim Galore (v0.4.4) software. SPAdes [54] (v3.12.0) was used to assemble the short reads into 134 contigs with a length greater than $500 \mathrm{bp}$. The regions around the gene (Fig. 4) were scaffolded from contigs 1, 3, 62, 83 and 89 using the previously recovered integron sequence (GenBank accession: AJ786649.2) and by manually exploring De Bruijn graphs with the Bandage software [55] (v0.8.1) as well as experimental control by PCR.

\section{Multi-locus sequence typing}

Contigs were searched against the PubMLST database [56]. P. aeruginosa 105MG was previously classified as ST227 [33], but whole genome sequencing resulted in a single nucleotide difference in the mutL allele changing the sequence type to ST235.

\section{Metagenome search}

The abundance of gar was searched in 1251 public metagenomic datasets (Additional file 2). Diamond [51] (v0.9.24.125) was used to map the reads to the reference protein with $100 \%$ identity and an ORF-length greater than 20 amino acids. To study the genetic context around the novel ARG, short reads from selected metagenomic datasets were mapped to the reference sequences from $P$. aeruginosa 105MG and Luteimonas sp. 83-4 using Bowtie 2 [57] (v2.2.9). Integron attachment sites were detected by identifying marginal paired-end reads using the Tablet software [58] (v1.19.05).

\section{Phylogenetic trees}

Sequences of the 1000 proteins most closely related to GAR were collected using three iterations of PSI-BLAST [59] on the NCBI non-redundant protein database. The retrieved proteins, GAR and all aminoglycoside resistance proteins from ResFinder were aligned with MAFFT [60] (v7.310). The phylogenetic tree was calculated by FastTree [61] (v2.1.9) using the maximum likelihood algorithm, Jones-Taylor-Thornton model, with 1000 bootstraps. Protein accession numbers and the full version of the tree are available in Additional files 3 and 4. The Interactive Tree Of Life (iTOL v4) online tool [62] was used to prepare the phylogenetic tree for display.

\section{Protein model}

The I-TASSER server for protein structure and function prediction was used to create models of GAR [63]. The model with the highest confidence score (C-score, 0.21) is shown. DeepView/Swiss-PdbViewer [64] (v4.1.0) was used to create the ribbon presentation.

\section{Supplementary information}

Supplementary information accompanies this paper at https://doi.org/10. 1186/s40168-020-00814-Z.

Additional file 1. Supplementary Material. Table S1. Cationdependency: MIC gentamicin $[\mu \mathrm{g} / \mathrm{ml}]$ of GAR in different media. Table S2. Chemical structure of the tested aminoglycosides and resistance profile conveyed by GAR. Table S3. Predicted and determined resistances of Pseudomonas aeruginosa 105MG. Table S4. Predicted resistances of Luteimonas sp. 83-4. Table S5. Occurrence of gar in 1251 metagenomic datasets.

Additional file 2. List of metagenomes searched for the presence of gar.

Additional file 3. Accession numbers of protein sequences used to calculate the phylogenetic tree.

Additional file 4. Phylogenetic tree of AMEs, GAR and the most closely related proteins in Newick format.

Additional file 5. Detailed material and methods.

Abbreviations

AAC: Aminoglycoside N-acetyltransferase; AME: Aminoglycoside modifying enzyme; ANT: Aminoglycoside O-nucleotidyltransferase; APH: Aminoglycoside O-phosphotransferase; ARG: Antibiotic resistance gene; ICE: Integrative conjugative element; MIC: Minimal inhibitory concentration; MLST: Multilocus sequence typing; ORF: Open reading frame; ST: Sequence type 


\section{Acknowledgements}

We thank Professors C. Giske and G. Rossolini for providing P. aeruginosa 105MG. Sequencing was conducted at the Swedish National Genomics Infrastructure (NGI) at the Science for Life Laboratories in Uppsala.

\section{Authors' contributions}

M.B. performed the experiments and analysed the data. M.R. performed the bioinformatics analyses. D.G.J.L, M.B., M.R., N.P.M. and C.F. designed the study. D.G.J.L supervised the study. M.B. wrote the manuscript with input from all co-authors. All authors read and approved the final manuscript.

\section{Funding}

This work was funded by the Swedish Research Council for Environment, Agriculture and Spatial Planning (FORMAS) (2018-00787 to D.G.J.L and 201800833 to C.F.), the Swedish Research Council (VR) (2018-02835 and 201805771 to D.G.J.L), the Swedish state under the agreement between the Swedish government and the county councils, the ALF-agreement to D.G.J.L. (grant number ALFGBG-717901) and the Centre for Antibiotic Resistance Research (CARe) at the University of Gothenbur. Open access funding provided by University of Gothenburg.

\section{Availability of data and materials}

Functional metagenomics sequencing data are available in Bioproject PRJNA555822, P. aeruginosa 105MG assembly in GenBank, accession VLOE00000000; and genetic context of gar from functional metagenomics in GenBank, accession MN215968.

\section{Ethics approval and consent to participate} Not applicable.

\section{Consent for publication}

Not applicable.

\section{Competing interests}

The authors declare that they have no competing interests.

\section{Author details}

${ }^{1}$ Centre for Antibiotic Resistance Research (CARe), University of Gothenburg, Gothenburg, Sweden. ${ }^{2}$ Department of Infectious Diseases, Institute of Biomedicine, Sahlgrenska Academy, University of Gothenburg, Gothenburg, Sweden. ${ }^{3}$ Institute of Marine Research (IMR), Bergen, Norway.

\section{Received: 19 December 2019 Accepted: 2 March 2020}

\section{Published online: 20 March 2020}

\section{References}

1. Bengtsson-Palme J, Kristiansson E, Larsson DGJ. Environmental factors influencing the development and spread of antibiotic resistance. FEMS Microbiol Rev. 2017:42:12. https://doi.org/10.1093/femsre/fux053.

2. Schwarz S, Johnson AP. Transferable resistance to colistin: a new but old threat. J Antimicrob Chemother. 2016;71:2066-70. https://doi.org/10.1093/ jac/dkw274.

3. Forsberg KJ, Patel S, Gibson MK, Lauber CL, Knight R, Fierer N, et al. Bacterial phylogeny structures soil resistomes across habitats. Nature. 2014;509:612-6. https://doi.org/10.1038/nature13377.

4. Versluis D, Rodriguez de Evgrafov M, MOA S, Sipkema D, Smidt H, van MWJ P. Sponge microbiota are a reservoir of functional antibiotic resistance genes. Front Microbiol. 2016:7:1848. https://doi.org/10.3389/fmicb.2016.01848.

5. Dos Santos DFK, Istvan P, Quirino BF, Kruger RH. Functional metagenomics as a tool for identification of new antibiotic resistance genes from natural environments. Microb Ecol. 2017;73:479-91. https://doi.org/10.1007/s00248016-0866-x.

6. Martínez $\mathrm{JL}$, Coque TM, Baquero F. What is a resistance gene? Ranking risk in resistomes. Nat Rev Microbiol. 2015;13:116-23. https://doi.org/10.1038/ nrmicro3399.

7. Cambray G, Guerout A-M, Mazel D. Integrons. Annu Rev Genet. 2010;44: 141-66. https://doi.org/10.1146/annurev-genet-102209-163504.

8. Gillings $M$, Boucher $Y$, Labbate $M$, Holmes A, Krishnan S, Holley M, et al. The evolution of class 1 integrons and the rise of antibiotic resistance. J Bacteriol. 2008;190:5095-100. https://doi.org/10.1128/JB.00152-08.
9. Razavi M, Marathe NP, Gillings MR, Flach C-F, Kristiansson E, Joakim Larsson DG. Discovery of the fourth mobile sulfonamide resistance gene. Microbiome. 2017;5:160. https://doi.org/10.1186/s40168-017-0379-y.

10. Marathe NP, Regina VR, Walujkar SA, Charan SS, Moore ERB, Larsson DGJ, et al. A treatment plant receiving waste water from multiple bulk drug manufacturers is a reservoir for highly multi-drug resistant integron-bearing bacteria. PLoS One. 2013;8:e77310. https://doi.org/10.1371/journal.pone.0077310.

11. Kristiansson E, Fick J, Janzon A, Grabic R, Rutgersson C, Weijdegård B, et al. Pyrosequencing of antibiotic-contaminated river sediments reveals high levels of resistance and gene transfer elements. PLoS One. 2011;6:e17038. https://doi.org/10.1371/journal.pone.0017038.

12. González $\sqcup$, Bahr G, Nakashige TG, Nolan EM, Bonomo RA, Vila AJ. Membrane anchoring stabilizes and favors secretion of New Delhi metallo- $\beta$-lactamase. Nat Chem Biol. 2016;12:516-22. https://doi.org/10.1038/nchembio.2083.

13. Johnson JW, Fisher JF, Mobashery S. Bacterial cell-wall recycling. Ann N Y Acad Sci. 2013;1277:54-75. https://doi.org/10.1111/j.1749-6632.2012.06813.x.

14. Koshland D, Botstein D. Secretion of beta-lactamase requires the carboxy end of the protein. Cell. 1980;20:749-60. https://doi.org/10.1016/00928674(80)90321-9.

15. Ramirez MS, Nikolaidis N, Tolmasky ME. Rise and dissemination of aminoglycoside resistance: the aac(6')-Ib paradigm. Front Microbiol. 2013;4: 121. https://doi.org/10.3389/fmicb.2013.00121.

16. Ramirez MS, Tolmasky ME. Aminoglycoside modifying enzymes. Drug Resist Updat. 2010;13:151-71. https://doi.org/10.1016/j.drup.2010.08.003.

17. Becker B, Cooper MA. Aminoglycoside antibiotics in the 21 st century. ACS Chem Biol. 2013;8:105-15. https://doi.org/10.1021/cb3005116.

18. Matte A, Delbaere LTJ. ATP-binding motifs. Encyclopedia of life sciences. Chichester: Wiley; 2010.

19. Noda Y, Yoda K, Takatsuki A, Yamasaki M. TmrB protein, responsible for tunicamycin resistance of Bacillus subtilis, is a novel ATP-binding membrane protein. J Bacteriol. 1992;174:4302-7. https://doi.org/10.1128/jb.174.13.43024307.1992.

20. Kapp U, Macedo S, Hall DR, Leiros I, McSweeney SM, Mitchell E. Structure of Deinococcus radiodurans tunicamycin-resistance protein (TmrD), a phosphotransferase. Acta Cryst. 2008;F64:479-86. https://doi.org/10.1107/ S1744309108011822

21. Walker JE, Saraste M, Runswick MJ, Gay NJ. Distantly related sequences in the alpha- and beta-subunits of ATP synthase, myosin, kinases and other ATP-requiring enzymes and a common nucleotide binding fold. EMBO J. 1982;1:945-51. https://doi.org/10.1002/j.1460-2075.1982.tb01276.x.

22. Koonin EV. A superfamily of ATPases with diverse functions containing either classical or deviant ATP-binding motif. J Mol Biol. 1993;229:1165-74. https://doi.org/10.1006/jmbi.1993.1115.

23. Leipe DD, Koonin EV, Aravind L. Evolution and classification of P-loop kinases and related proteins. J Mol Biol. 2003;333:781-815. https://doi.org/ 10.1016/j.jmb.2003.08.040.

24. Wright GD, Thompson PR. Aminoglycoside phosphotransferases: proteins, structure, and mechanism. Front Biosci. 1999;4:D9-21. https://doi.org/10. 2741/wright.

25. Smith CA, Toth M, Bhattacharya M, Frase H, Vakulenko SB. Structure of the phosphotransferase domain of the bifunctional aminoglycoside-resistance enzyme AAC(6')-le-APH(2")-la. Acta Cryst. 2014;D70:1561-71. https://doi.org/ 10.1107/S1399004714005331.

26. Miller JM, Enemark EJ. Fundamental characteristics of AAA+ protein family structure and function. Archaea. 2016;2016:9294307. https://doi.org/10.1155/ 2016/9294307.

27. Doroghazi JR, Ju K-S, Brown DW, Labeda DP, Deng Z, Metcalf WW, et al. Genome sequences of three tunicamycin-producing Streptomyces strains, S. chartreusis NRRL 12338, S. chartreusis NRRL 3882, and S. lysosuperificus ATCC 31396. J Bacteriol. 2011;193:7021-2. https://doi.org/10.1128/JB.06262-11.

28. Allen HK, Moe LA, Rodbumrer J, Gaarder A, Handelsman J. Functional metagenomics reveals diverse $\beta$-lactamases in a remote Alaskan soil. ISME J. 2009:3:243-51. https://doi.org/10.1038/ismej.2008.86.

29. Lau CH-F, van Engelen K, Gordon S, Renaud J, Topp E. Novel antibiotic resistance determinants from agricultural soil exposed to antibiotics widely used in human medicine and animal farming. Appl Environ Microbiol. 2017. https://doi.org/10.1128/AEM.00989-17.

30. Berglund F, Marathe NP, Österlund T, Bengtsson-Palme J, Kotsakis S, Flach C$F$, et al. Identification of 76 novel B1 metallo- $\beta$-lactamases through largescale screening of genomic and metagenomic data. Microbiome. 2017;5: 134. https://doi.org/10.1186/s40168-017-0353-8. 
31. Forsberg KJ, Reyes A, Wang B, Selleck EM, Sommer MOA, Dantas G. The shared antibiotic resistome of soil bacteria and human pathogens. Science. 2012:337:1107-11. https://doi.org/10.1126/science.1220761.

32. Riesenfeld CS, Goodman RM, Handelsman J. Uncultured soil bacteria are a reservoir of new antibiotic resistance genes. Environ Microbiol. 2004;6:981-9. https://doi.org/10.1111/j.1462-2920.2004.00664.x.

33. Giske CG, Libisch B, Colinon C, Scoulica E, Pagani L, Füzi M, et al. Establishing clonal relationships between VIM-1-like metallo-beta-lactamaseproducing Pseudomonas aeruginosa strains from four European countries by multilocus sequence typing. J Clin Microbiol. 2006:44:4309-15. https:// doi.org/10.1128/JCM.00817-06.

34. Oliver A, Mulet $X$, López-Causapé C, Juan C. The increasing threat of Pseudomonas aeruginosa high-risk clones. Drug Resist Updat. 2015;21-22: 41-59. https://doi.org/10.1016/j.drup.2015.08.002

35. Bassetti M, Vena A, Croxatto A, Righi E, Guery B. How to manage Pseudomonas aeruginosa infections. Drugs Context. 2018;7:212527. https:// doi.org/10.7573/dic.212527.

36. Scallan E, Hoekstra RM, Angulo FJ, Tauxe RV, Widdowson M-A, Roy SL, et al. Foodborne illness acquired in the United States - major pathogens. Emerging Infect Dis. 2011;17:7-15. https://doi.org/10.3201/eid1701.p11101.

37. EFSA, ECDC. The European Union One Health 2018 Zoonoses Report. European Centre for Disease Prevention and Control; 2019.

38. McDermott PF, Zhao S, Tate H. Antimicrobial resistance in nontyphoidal Salmonella. Microbiol Spectr. 2018;6. https://doi.org/10.1128/microbiolspec. ARBA-0014-2017.

39. Achaogen. UPDATE -- ZEMDRI ${ }^{\mathrm{TM}}$ (plazomicin) Approved by FDA for the Treatment of Adults with Complicated Urinary Tract Infections (CUTI): Achaogen Inc.; 2018 [10 Dez 2019]. Available from: http://investors. achaogen.com/news-releases/news-release-details/update-zemdritmplazomicin-approved-fda-treatment-adults files/8545/update-zemdritmplazomicin-approved-fda-treatment-adults.html.

40. Cox G, Ejim L, Stogios PJ, Koteva K, Bordeleau E, Evdokimova E, et al. Plazomicin retains antibiotic activity against most aminoglycoside modifying enzymes. ACS Infect Dis. 2018;4:980-7. https://doi.org/10.1021/acsinfecdis.8b00001.

41. Nicolas E, Lambin M, Dandoy D, Galloy C, Nguyen N, Oger CA, et al. The Tn3-family of replicative transposons. Microbiol Spectr. 2015;3. https://doi. org/10.1128/microbiolspec. MDNA3-0060-2014.

42. Liebert CA, Hall RM, Summers AO. Transposon Tn21, flagship of the floating genome. Microbiol Mol Biol Rev. 1999;63:507-22 http://www.ncbi.nlm.nih. gov/pubmed/10477306.

43. Toleman MA, Biedenbach D, Bennett D, Jones RN, Walsh TR. Genetic characterization of a novel metallo- $\beta$-lactamase gene, bla $a_{1 \mathrm{MP}-13,}$, harboured by a novel Tn5051-type transposon disseminating carbapenemase genes in Europe: report from the SENTRY worldwide antimicrobial surveillance programme. J Antimicrob Chemother. 2003;52:583-90. https://doi.org/10. 1093/jac/dkg410.

44. Ghaly TM, Chow L, Asher AJ, Waldron LS, Gillings MR. Evolution of class 1 integrons: mobilization and dispersal via food-borne bacteria. PLoS One. 2017;12:e0179169. https://doi.org/10.1371/journal.pone.0179169.

45. Cury J, Jové T, Touchon M, Néron B, Rocha EP. Identification and analysis of integrons and cassette arrays in bacterial genomes. Nucleic Acids Res. 2016; 44:4539-50. https://doi.org/10.1093/nar/gkw319.

46. Gillings MR. Class 1 integrons as invasive species. Curr Opin Microbiol. 2017; 38:10-5. https://doi.org/10.1016/j.mib.2017.03.002.

47. Gillings MR. DNA as a pollutant: the clinical class 1 integron. Curr Pollution Rep. 2018;4:49-55. https://doi.org/10.1007/s40726-018-0076-X.

48. Huijbers PMC, Flach C-F, Larsson DGJ. A conceptual framework for the environmental surveillance of antibiotics and antibiotic resistance. Environ Int. 2019;130:104880. https://doi.org/10.1016/j.envint.2019.05.074.

49. Hyatt D, Chen G-L, Locascio PF, Land ML, Larimer FW, Hauser LJ. Prodigal: prokaryotic gene recognition and translation initiation site identification. BMC Bioinformatics. 2010;11:119. https://doi.org/10.1186/1471-2105-11-119.

50. Zankari E, Hasman H, Cosentino S, Vestergaard M, Rasmussen S, Lund O, et al. Identification of acquired antimicrobial resistance genes. J Antimicrob Chemother. 2012;67:2640-4. https://doi.org/10.1093/jac/dks261.

51. Buchfink $B$, Xie $C$, Huson DH. Fast and sensitive protein alignment using DIAMOND. Nat Methods. 2015;12:59-60. https://doi.org/10.1038/nmeth.3176.

52. CLSI. Methods for dilution antimicrobial susceptibility tests for bacteria that grow aerobically: M07-A9; approved standard. 9th ed. Wayne, PA 19087 USA: Committee for Clinical Laboratory Standards Institute; 2012.
53. Schuurmans JM, Nuri Hayali AS, Koenders BB, ter Kuile BH. Variations in MIC value caused by differences in experimental protocol. J Microbiol Methods. 2009;79:44-7. https://doi.org/10.1016/j.mimet.2009.07.017.

54. Bankevich A, Nurk S, Antipov D, Gurevich AA, Dvorkin M, Kulikov AS, et al. SPAdes: a new genome assembly algorithm and its applications to singlecell sequencing. J Comput Biol. 2012;19:455-77. https://doi.org/10.1089/ $\mathrm{cmb} .2012 .0021$

55. Wick RR, Schultz MB, Zobel J, Holt KE. Bandage: interactive visualization of de novo genome assemblies. Bioinformatics. 2015;31:3350-2. https://doi. org/10.1093/bioinformatics/btv383.

56. Jolley KA, Bray JE, Maiden MCJ. Open-access bacterial population genomics: BIGSdb software, the PubMLST.org website and their applications. Wellcome Open Res. 2018;3:124. https://doi.org/10.12688/wellcomeopenres.14826.1.

57. Langmead B, Salzberg SL. Fast gapped-read alignment with Bowtie 2. Nat Methods. 2012;9:357-9. https://doi.org/10.1038/nmeth.1923.

58. Milne I, Bayer M, Cardle L, Shaw P, Stephen G, Wright F, et al. Tablet--next generation sequence assembly visualization. Bioinformatics. 2010;26:401-2. https://doi.org/10.1093/bioinformatics/btp666.

59. Altschul SF, Madden TL, Schäffer AA, Zhang J, Zhang Z, Miller W, et al. Gapped BLAST and PSI-BLAST: a new generation of protein database search programs. Nucleic Acids Res. 1997;25:3389-402. https://doi.org/10.1093/nar/ 25.17.3389.

60. Katoh K, Standley DM. MAFFT multiple sequence alignment software version 7: improvements in performance and usability. Mol Biol Evol. 2013; 30:772-80. https://doi.org/10.1093/molbev/mst010.

61. Price MN, Dehal PS, Arkin AP. FastTree 2 - approximately maximumlikelihood trees for large alignments. PLoS One. 2010;5:e9490. https://doi. org/10.1371/journal.pone.0009490.

62. Letunic I, Bork P. Interactive Tree Of Life (iTOL) v4: recent updates and new developments. Nucleic Acids Res. 2019;47:W256-W9. https://doi.org/10. 1093/nar/gkz239.

63. Roy A, Kucukural A, Zhang Y. I-TASSER: a unified platform for automated protein structure and function prediction. Nat Protoc. 2010;5:725-38. https:// doi.org/10.1038/nprot.2010.5

64. Guex N, Peitsch MC. SWISS-MODEL and the Swiss-Pdb Viewer: An environment for comparative protein modeling. Electrophoresis. 1997;18: 2714-23. https://doi.org/10.1002/elps.1150181505.

\section{Publisher's Note}

Springer Nature remains neutral with regard to jurisdictional claims in published maps and institutional affiliations.

Ready to submit your research? Choose BMC and benefit from:

- fast, convenient online submission

- thorough peer review by experienced researchers in your field

- rapid publication on acceptance

- support for research data, including large and complex data types

- gold Open Access which fosters wider collaboration and increased citations

- maximum visibility for your research: over $100 \mathrm{M}$ website views per year

At $\mathrm{BMC}$, research is always in progress.

Learn more biomedcentral.com/submission 